American Journal of Environmental Sciences 7 (5): 463-467, 2011

ISSN 1553-345X

(C) 2011 Science Publications

\title{
Clamshell vs. Backhoe Excavation of Permeable Reactive Barriers
}

\author{
${ }^{1}$ Rajandrea Sethi, ${ }^{2}$ Steve Day and ${ }^{1}$ Antonio Di Molfetta \\ ${ }^{1}$ DITAG-Politecnico di Torino, C.so Duca degli Abruzzi 24, Torino, 10129, Italy \\ ${ }^{2}$ Geo-Solutions Inc., 26 West Dry Creek Circle, Suite 600, Littleton, Colorado, 80120, USA
}

\begin{abstract}
Problem statement: Permeable Reactive Barriers (PRBs) were one of the most widespread solutions for the remediation of contaminated aquifers. Although, a variety of excavation methods had been developed, backhoe (hydraulic excavators) were commonly used for the construction of PRBs in North America. Approach: In Europe, the most common method of slurry excavation was with a hydraulic grab and crane. The aim of this study was to compare clamshell and backhoe excavation techniques and to describe the installation of a full scale PRB using a crawler crane equipped with a hydraulic grab. Results: Backhoes had been used on a larger number of PRB installations and permit a rapid rate of excavation and generally require less skill to master. Long stick backhoes were capable of digging as deep as $30 \mathrm{~m}$. Instead, clamshell excavators require more skill to use, but were able to excavate to a depth of more than $70 \mathrm{~m}$, with a high degree of precision. Two similar case studies were presented to compare the relative merits of the two excavation techniques. Conclusion/Recommendations: The first describes a funnel and gate system excavated by long stick backhoe, in the US, whose longest gate is $0.73 \mathrm{~m}$ thick, $68 \mathrm{~m}$ long and up to $13 \mathrm{~m}$ deep. The latter is a $0.6 \mathrm{~m}$ thick, $120 \mathrm{~m}$ long and $13 \mathrm{~m}$ deep continuous PRB, excavated by crane mounted grab to remediate a chlorinated hydrocarbons plume, in Avigliana, near the city of Torino, in Italy. Comparison of the two techniques is performed on the availability of instrumentation, excavation power and precision, potential for cost savings.
\end{abstract}

Key words: Permeable reactive barrier, groundwater, excavation, zerovalent iron

\section{INTRODUCTION}

Iron-based PRBs have evolved from innovative to accepted standard practice for the treatment of a variety of groundwater contaminants, which offers a simple, less costly solution to groundwater cleanup (Gillham and O'Hannesin, 1994). A PRB is constructed underground, across the flow path of a contaminant plume. As the groundwater passes through the PRB, the contaminants are precipitated, adsorbed or degraded by the millimetric zerovalent iron in the PRB with treated groundwater emerging on the down-gradient side. This passive type of remediation results in reduced costs due to the semi-permanent installation, lack of external energy input, reduced monitoring requirements, conservation of clean water and continued productive use of the site almost immediately after installation. If the source of contaminant has been identified a treatment of the non-aqueous phase liquid (Godio et al., 2010) can be performed, instead, by injection of microscale or nanoscale zerovalent iron (Tiraferri et al., 2011; Saleh et al., 2007; Comba et al., 2011a) directly in the aquifer.

The construction of PRBs requires installation below the groundwater table and often to substantial depths on dangerous and difficult sites. Although, new constructive techniques were studied and adapted from geotechnical field (Day et al., 1999), PRBs are most often installed using backhoe excavators.

For many of these sites, the Bio-Polymer (BP) slurry drainage trench can provide better, faster, cheaper and safer installations. The BP trench installation offers the following advantages:

- Maintains the dimensions of the installation to avoid wasting costly reactive materials without expensive shoring or sheeting

- Eliminates dewatering and subsequent treatment of contaminated groundwater during construction

- Minimizes safety risks by eliminating entry into the trench and suppressing toxic or unpleasant odors

- Provides a rapid and simple construction sequence

- Adaptable to a variety of soil types and sites

- Provides ensured continuity, superior to other installation methods; is less costly than most other methods

\section{MATERIALS AND METHODS}

The excavation and filling phases of the BP shored PRB can be roughly summarized as follows (Day et al., 1999; Molfetta and Sethi, 2006):

Corresponding author: Rajandrea Sethi, DITAG-Politecnico di Torino, C.so Duca degli Abruzzi 24, Torino, 10129, Italy 
- Installation of guide wall (if crane with grab is used) to facilitate excavation and contain the biopolymer slurry

- Excavation of a panel supporting the trench with biopolymer slurry

- Positioning of a steel End Stop (ES) in order to separate excavation and backfilling operations between neighbouring panels

- Positioning of a screened, Temporary Well (ET) in the middle of the panel for breaker recirculation when degrading the slurry

- Displacement of the slurry with Zero Valent Iron (ZVI) and sand mix

- Extraction of the ES and excavation of the next panel

At the end of excavation and filling of the PRB it's necessary to break down the biopolymer slurry by enzyme (breaker) recirculation and fill the top of the trench with an impermeable cap.

After reagent, the most important construction cost factor is soil conditions. On PRBs with a moderate depth (about $15 \mathrm{~m}$ deep), creating and installing the backfill is the most important production factor. However, as the depth of the trench gets deeper, the rate of excavation becomes more important in the cost and rate of production.

The PRB installation methods have evolved and been better perfected over the last decade. Three principal and linked activities are involved in construction: excavation under slurry, slurry production and backfilling. Production is determined by the slower of the three at shallow to moderate depths and in easily excavated soils. In these conditions, backfilling determines production. At deeper depths and in more difficult soils the rate of excavation will determine production.

One element that is critical to successful PRB installation is the excavation of the trench. Currently, there are basically two methods in common usage for excavating deep and narrow trenches and slurry walls: in the US typical excavation is with hydraulic Long Stick excavator (LS excavators) or backhoe; in Europe, excavation typically uses crane with clam bucket.

Long stick backhoes are hydraulic-powered machines that are modified versions of conventional hydraulic excavators. The enhancement of these machines consists in an oversized arm (stick and/or boom) that is extended to be able to study at deeper depths. In backhoe excavators the combination of stick crowd Force $\left(\mathrm{F}_{\mathrm{S}}\right)$ and bucket curling Force $\left(\mathrm{F}_{\mathrm{B}}\right)$ determines the penetration of bucket into soil (Fig. 1).

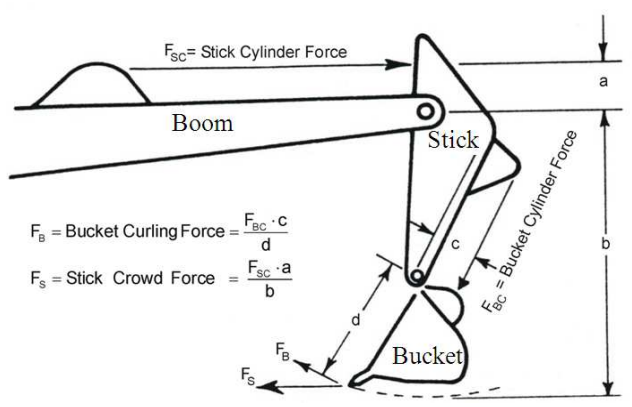

Fig. 1: Backhoe excavators forces

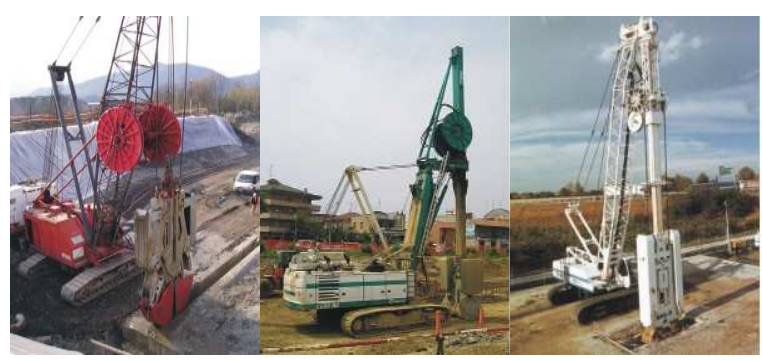

(a)

(b)

(c)

Fig. 2: Crane excavators: (a) Rope suspended; (b) Kelly mounted; (c) Hybrid system

Both forces are function of the hydraulic relief pressure generated inside cylinders but, while bucket curling force is independent from stick length, stick crowd force is inversely proportional to this length. Thus the longer the stick, the greater should be the corresponding relief pressure and power of the machine, to generate the same force on tip of the bucket.

Commonly employed excavators for PRB emplacement weight $80,000 \mathrm{~kg}$, are equipped with diesel engine with at least $280 \mathrm{~kW}$ and capable of excavate down to $15 \mathrm{~m}$ (see Table 1). Larger and more powerful machines are able to reach depths in excess of $25 \mathrm{~m}$. LS excavators are usually equipped with a relatively small digging bucket, $0.7-1 \mathrm{~m}^{3}$ capacity, 0.6-1 $\mathrm{m}$ wide. In average soils these machines can often excavate to $400 \mathrm{~m}^{2}$ per working day.

The grab bucket excavator was developed in early 60 s by an Italian company called ICOS that also introduced the concept of diaphragm wall (Puller, 2003). Nowadays crane with grab bucket (clam excavator) is the more common excavating machine in Europe. Clam excavators could use rope, kelly bar or a hybrid system to suspend the clam during excavation (Fig. 2). Rope suspended grabs could reach greater depths but with a lower degree of precision if compared to Kelly mounted systems. Hybrid cranes combine the functionality and advantages offered by the two systems. 
Am. J. Environ. Sci., 7 (5): 463-467, 2011

Table 1: Backhoe and Grab excavator's specifications

\begin{tabular}{lll}
\hline & Backhoe excavators $^{1}$ & Grab excavators $^{2}$ \\
\hline Max. power & $50-485 \mathrm{~kW}$ & $240-400 \mathrm{~kW}$ \\
Base machine weight & $7,000-110,000 \mathrm{~kg}$ & $42,000-300,000 \mathrm{~kg}$ \\
Lifting capacity & $3,500-40,000 \mathrm{~kg}$ & $20,000-30,000 \mathrm{~kg}$ \\
Weight of bucket/grab & $300-3,000 \mathrm{~kg}$ & $8,000-24,000(\mathrm{~kg})$ \\
Excavation width & $0.4-3.0(\mathrm{~m})$ & $0.5-1.2(\mathrm{~m})$ \\
Excavation length & - & $2-4.2(\mathrm{~m})$ \\
Capacity of bucket/grab & $0.2-1 \mathrm{~m}^{3}$ & $1-1.2 \mathrm{~m}^{3}$ \\
Bucket/grab digging & $50-430 \mathrm{kN}$ & $300-400 \mathrm{kN}$ \\
Stick crowd force & inversely proportional \\
force (ISO) & to stick length & - \\
Excavation depths & $0-30 \mathrm{~m}$ & $5-70 \mathrm{~m}^{2}$ \\
Excavation rate & $400 \mathrm{~m}^{2}$ day ${ }^{1}$ & $300 \mathrm{~m}^{2}$ day $^{1}$ \\
\hline${ }^{1}$ CAT, Link Belt, Komatsu (model 1250 or lower) \\
${ }^{2}$ Casagrande, SoilMec, Bauer, Soletanche Bachy
\end{tabular}

Some clam excavators can be equipped with automatic systems to improve panel excavation tolerances and overall quality control standards. Grabs can be mechanically or hydraulically operated, in both cases the closing force is independent from depth thus exploiting better power of the machine.

Usually, the crane weights about $100,000 \mathrm{~kg}$ and the clam weighs about $7,000 \mathrm{~kg}$ (Table 1). These machines are capable of excavating to depths of 30-40 m, more powerful machines to depths of $70 \mathrm{~m}$. In average soils can often excavate to $300 \mathrm{~m}^{2}$ per working day.

\section{RESULTS}

Two similar case studies are presented to compare merits of the presented excavation techniques.

Long Stick Excavator case study. A funnel and gate was designed to remediate a complex combination of contaminates leaking from a closed chemical landfill in US. The plume contained TCE, PCB and other contaminants. The site is located along the US Gulf Coast on a high spot in a swamp and formerly serviced industrial and government clients. The funnel and gate system consisted of four soil-bentonite slurry walls and three ZVI-sand gates. The largest gate was $0.73 \mathrm{~m}$ wide, $68 \mathrm{~m}$ long and up to $13 \mathrm{~m}$ deep. The system was constructed in the heat and humidity of the summer.

The construction of the PRB began with a levelling of the area under the supervision of Geo-Solutions. The trench was excavated with a Komatsu PC750 hydraulic excavator with an extended stick extended to dig up to $20 \mathrm{~m}$ (Fig. 3). The bucket was $0.72 \mathrm{~m}$ wide and had a capacity of $0.9 \mathrm{~m}^{3}$. The excavation was divided into 3 panels and used bio-polymer slurry to retain the trench walls. (a)

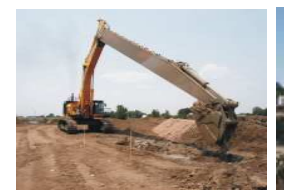

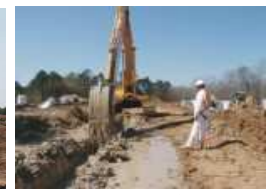

(b)
Fig. 3: Long stick excavator case study

The excavation was performed by digging from the surface to the aquiclude in "cuts" about $10 \mathrm{~m}$ long each. The cuts were joined by removing the intervening soil with the excavator to create a continuous trench. Temporary end stops were placed at approximately 20 $m$ intervals, with permanent end stops between the soilbentonite and the PRB. The ES were positioned by a service crane and then pushed into the aquiclude by the excavator. The slurry was made in a batch mixing plant made up of custom made in a bio-polymer eductor, colloidal mixer and storage tanks. Each batch was prepared using about $1 \mathrm{~m}^{3}$ of tap water, $7 \mathrm{~kg}$ of guar gum (Comba et al., 2011b; Tosco and Sethi, 2010) and preserved with soda ash and biocide as required by site demands. After mixing, the slurry was stored and recirculated in a $75 \mathrm{~m}^{3}$ frac tank.

After the excavation of each panel and before filling it with the ZVI-sand mix, a slotted tube for breaker recirculation (ET) was inserted. The ZVI-sand mix containing $42 \%$ (by volume) of iron was prepared off site, loaded into readymix concrete trucks and then placed into the trench through a tremie pipe. ZVI-sand proportions were weighed and double checked by magnetic separation testing. A total of 500 metric tons of iron were used to backfill the trench. Excavation and backfilling of the PRB was accomplished in 6 days.

Breakdown of guar gum was initiated by injecting the breaker solution into the recirculation tubes (ET) and air lifting was used to circulate the enzymes solution from the bottom of the wells and through the ZVI-sand material. At least 2 pore volumes of degraded slurry and water were recirculated by the air lift pumps. At the end of this operation Marsh Funnel viscosity was less than $30 \mathrm{sec}$ relative to $>80 \mathrm{sec}$ of virgin slurry.

A sand layer overlain by an impermeable clayey cap was placed on the top of the permeable reactive barrier to prevent oxidation of the iron.

Clam excavator case study. In this paragraph is presented the construction of the first full scale installation of a PRB by means of clam excavator. The PRB was designed to remediate a chlorinated hydrocarbons plume, containing both TCE (maximum concentrations of $130 \mu \mathrm{g} \mathrm{L}^{1}$ ) and cDCE (maximum concentrations of $135 \mu \mathrm{g} \mathrm{\textrm {L } ^ { 1 }}$ ), at an old industrial landfill site, in Avigliana, near the city of Torino, in Italy (Bonomo, 2005). 
Am. J. Environ. Sci., 7 (5): 463-467, 2011

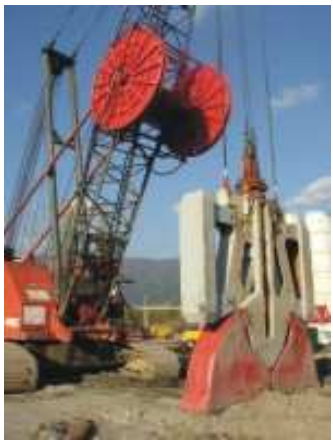

Fig. 4: Crawler crane equipped and hydraulic grab used in the excavation

The continuous reactive barrier was designed to be 120 $\mathrm{m}$ long, $13 \mathrm{~m}$ deep and $0.6 \mathrm{~m}$ long.

The construction of the PRB began with several site preparation activities including the flatting of the area and the construction of a guide wall to facilitate slurry excavation using a grab excavator.

The trench excavation was performed by Rodio Division, Trevi S.p.A., by means of a Link Belt LS338 crawler crane equipped with a Casagrande K4000 hydraulic grab (Fig. 4). The grab was $0.6 \mathrm{~m}$ wide, $4 \mathrm{~m}$ long and with a volumetric load capacity of $1 \mathrm{~m}^{3}$. The excavation was divided into 17 panels and biopolymer slurry was used as shoring fluid.

Depending on the variable length of the panel, the excavation was performed in two or three operations. At the beginning, the lateral portions of the panel were excavated and then the central part was removed. To avoid scraping the grab, the excavation of each section was extended 1 meter into the leading panel in order to leave enough room for the insertion of the tubular end stop. The $15 \mathrm{~m}$ long and $0.6 \mathrm{~m}$ diameter ES tubes were inserted inside the guide wall by a support crane and into the subsoil till aquiclude. The ES were supported by grooves in the guide walls.

The slurry was made in a batch mixing plant made up of eductor, colloidal mixer and cylindrical tanks. Each batch was prepared using $3.5 \mathrm{~m}^{3}$ of tap water, 25 $\mathrm{kg}$ of guar gum and preserved soda ash and biocide as required by site demands. A bentonite mixing tank was used to make the slurry which was just barely adequate for mixing biopolymer slurry. After mixing, the slurry was stored and recirculated in $50 \mathrm{~m}^{3}$ tanks.

After the excavation of each panel and before filling it with ZVI-sand mix, a slotted tube for breaker recirculation (ET) was inserted. The ZVI-sand mix containing $83 \%$ (by volume) of iron was prepared in two parallel hoppers, loaded into readymix concrete trucks and then placed into the trench trough a tremie pipe. ZVI and sand proportions were controlled by weight-volume relationships and checked with magnetic separation testing. A total amount of 1,700 metric tons of iron were used to backfill the trench. Excavation and backfilling of the PRB was accomplished in 8 days.

Breakdown of guar gum was initiated by injecting a breaker solution into the recirculation tubes (ET) and air lifting was used to circulate the solution from the bottom of the wells and through the PRB. At least 2 pore volumes of degraded slurry and water were recirculated. At the end of this operation Marsh Funnel viscosity was less than $30 \mathrm{sec}$ relative to $>60 \mathrm{sec}$ of virgin slurry.

A sand layer overlain by an impermeable clay cap was placed on the top of the permeable reactive barrier to prevent oxidation of the iron.

\section{DISCUSSION}

Usage of bioslurry. The amount of slurry used in Avigliana was less than $500 \mathrm{~m}^{3}$, that is almost $52 \%$ of the total volume of the trench. This value is very low compared to most other case studies that report values higher than the volume of the trench (e.g., $140 \%$ in (Mountjoy and Blowes, 2002). Also in the gulf coast site the amount of slurry used was also about $500 \mathrm{~m}^{3}$, or about $89 \%$ of the total volume of the trench. Hot humid weather and the highly organic nature of the surrounding environment probably contributed to increasing the slurry usage. The amount of biopolymer slurry required is a function of soil type and ambient conditions, as wells as the use of a guide wall, excavation method and operator expertise. The reduction in the quantity of slurry and additives permitted faster construction in both cases. The lesser amount of slurry used at Avigliana is primarily due to the narrower top of the trench provided by the guide walls, shorter panel lengths and the ease in excavation of the silty-sandy soils.

Excavation speed. Excavation of the trench using a crane equipped with hydraulic grab in Avigliana was fast enough to allow construction of 3 panels in just 12 hours. The average productivity of the excavation and filling operations was around $18 \mathrm{~m}^{2} \mathrm{~h}^{1}$. With foresight, it may have been possible to speed up the work by lowering the number of the panels thus reducing redundant operations. In the gulf coast the excavation rate was similar with the Long Stick excavator. Since the guide wall is not required, the time for guide wall construction is eliminated. The additional cost of the guide wall may be justified if the cost of the extra biopolymer slurry is excessive. 


\section{CONCLUSION}

The selection of an excavator for a PRB installation depends on a number of factors, primarily availability and cost. In the USA long stick excavators are more available and can dig as deep as $30 \mathrm{~m}$. In Europe, cranes with grabs are more common and capable of deeper excavations (70 $\mathrm{m}$ maximum). Excavation rates for long stick excavators and cranes with grabs are similar in their same depth ranges. Long stick excavators (and standard hydraulic excavators) are more cost effective at shallower depths, while cranes with grabs are more cost effective as the trench becomes deeper. With any slurry trench excavation, the quicker the excavation the more economical the work.

The construction of the first full scale PRB by means of a crawler crane equipped with hydraulic grab (clamshell) proved to be an effective and affordable construction method. In 8 days it was possible to excavate a $120 \mathrm{~m}$ long and $13 \mathrm{~m}$ deep PRB and fill it with $1700 \mathrm{t}$ of iron, achieving an average productivity of $18 \mathrm{~m}^{2} \mathrm{~h}^{1}$. Fast excavation rates coupled to use of a concrete guide wall and of short panels, lead to contain the amount of used guar gum slurry to $50 \%$ of the volume of the trench (compared to 140\%, Mountjoy and Blowes, 2002) and increased the precision of excavation. Abating the production of biopolymer slurry was beneficial in restraining the amount of additives. Also the long term monitoring results confirm the correct installation of the PRB (Zolla et al., 2007a; 2007b).

\section{REFERENCES}

Comba, S., A.D. Molfetta and R. Sethi, 2011a. A comparison between field applications of nano-, micro- and millimetric zero-valent iron for the remediation of contaminated aquifers. Water, Air Soil Poll.., 215: 595-607. DOI: 10.1007/s11270010-0502-1

Comba, S., D. Dalmazzo, E. Santagata and R. Sethi, 2011b. Rheological characterization of xanthan suspensions of nanoscale iron for injection in porous media. J. Hazardous Mater., 185: 598-605. DOI: 10.1016/j.jhazmat.2010.09.060

Day, S.R., S.F. O'Hannesin and L. Marsden, 1999. Geotechnical techniques for the construction of reactive barriers. J. Hazard Mater., 67: 285-297. DOI: 10.1016/S0304-3894(99)00044-8

Bonomo, L., 2005. Bonifica di siti contaminati. Caratterizzazione e tecnologie di risanamento. 1st Edn., McGraw-Hill Companies, Milano, ISBN: 8838662789, pp: 715 .
Gillham, R.W. and S.F. O'Hannesin, 1994. Enhanced degradation of halogenated aliphatics by zerovalent iron. Ground Water, 32: 958-967. DOI: 10.1111/j.1745-6584.1994.tb00935.x

Godio, A., A. Arato and S. Stocco, 2010. Geophysical characterization of a nonaqueous-phase liquidcontaminated site. Environ. Geosci., 17:141-162. DOI: 10.1306/eg.04261010003

Mountjoy, K.J. and D. Blowes, 2002 Installation of a full-scale permeable reactive barrier for the treatment of metal-contaminated groundwater. Proceedings of the 3rd International Conference on Remediation of Chlorinated and Recalcitrant Compounds, May 20-23, Monterey, CA, USA., pp: 1-8.

Molfetta, A.D. and R. Sethi, 2006. Clamshell excavation of a permeable reactive barrier. Environ. Geol., 50: 361-369. DOI: 10.1007/s00254-006-0215-3

Puller, M., 2003. Deep Excavations: A Practical Manual. 2nd Edn., Thomas Telford, London, ISBN: 0727731505, pp: 571.

Saleh, N., K. Sirk, Y. Liu, T. Phenrat and B. Dufour et al., 2007. Surface modifications enhance nanoiron transport and NAPL targeting in saturated porous media. Environ. Eng. Sci. 24: 45-57. DOI: 10.1089/ees.2007.24.45

Tiraferri, A., T. Tosco and R. Sethi, 2011. Transport and retention of microparticles in packed sand columns at low and intermediate ionic strengths: experiments and mathematical modeling. Environ. Earth Sci., 63: 847-859. DOI: 10.1007/s12665-0100755-4

Tosco, T. and R. Sethi, 2010. Transport of nonnewtonian suspensions of highly concentrated micro- and nanoscale iron particles in porous media: a modeling approach. Environ. Sci. Technol., 44: 9062-9068. DOI: 10.1021/es100868n

Zolla, V., R. Sethi and A.D. Molfetta, 2007a. Performance assessment and monitoring of a permeable reactive barrier for the remediation of a contaminated site. Am. J. Environ. Sci., 3; 158-165. DOI: 10.3844/ajessp.2007.158.165

Zolla, V., F.S. Freyria, R. Sethi and A.D. Molfetta, 2007b. Hydrogeochemical and biological processes affecting the long-term performance of an ironbased permeable reactive barrier. J. Environ. Quality, 38: 897-908. DOI: 10.2134/jeq2007.0622 